American Journal of Biochemistry and Biotechnology 6 (3): 195-203, 2010

ISSN 1553-3468

(C) 2010 Science Publications

\title{
Amelioration of Inducible Nitric Oxide Synthase, Insulin like Growth Factor-1 Gene Expression and Insulin Receptor Substrate-1 in Liver Tissue of Insulin Resistant Rats Treated With L-Carnitine
}

\author{
Hala M. Ghanem \\ Department of Biochemistry, Faculty of Science, Ain Shams University, Egypt
}

\begin{abstract}
Problem statement: It has been reported that genes expression (inducible Nitric Oxide (iNOS). Insulin-like Growth Factor-1(IGF-1) have a role in both glucose homeostasis and insulin resistance. The aim of this study was designed to evaluate the amelioration of the iNOS, IGF-1 genes expression as well as IRS-1 in liver tissues of rats fed high fructose diet treated with Lcarnitine. Approach: About 24 male Wister rats of body weight 120-160 g were divided into 3 groups of 8 rats each. Group 1 received control diet, while group 2 and 3, rats received high fructose diet $(60 \mathrm{~g}$ $100 \mathrm{~g}^{-1}$ diet). Group 3, after 2 weeks from fructose feeding animals were treated with $\mathrm{L}$-carnitine (CA) (300 mg kg $\mathrm{body} \mathrm{weight} \mathrm{day}^{-1}$ i. p). At the end of the experimental period (30 days), serum levels of glucose, insulin, Triacylglycerol (TG) and cholesterol were determined. Hepatic contents of cholesterol, triacylglycerol, Malondialdehyde (MDA) and nitrogen oxide products were assayed. Genes expressions of iNOS, IGF-1 as well as IRS-1 were also determined in liver tissues of the experimental animals feeding high fructose diet. Results: Compared to control rats, the high fructose feeding in animals induces alterations in serum glucose, lipid metabolism and hepatic TG and MDA. In addition, fructose fed group develop marked increase in hepatic gene expression of iNOS and pronounced decreases in both IGF-1 mRNA and IRS-1 receptor. The administration of L-carnitine to rats fed high fructose diet mitigated the adverse effects of fructose load (insulin resistance) through the regulation of studied genes expression as well as insulin receptor substrate-1. Conclusion: The important findings of this context indicate the close association between hepatic gene expression (iNOS and IGF-1), IRS-1 receptor and insulin resistance. The exogenous CA to fructose fed rats improves the inflammation resulting from insulin resistance through the amelioration of the studied genes expression. This indicates that iNOS and IGF-1 have the characteristics to be marker of the metabolic syndrome.
\end{abstract}

Key words: Insulin resistance, L-carnitine, inducible Nitric Oxide (iNOS), hypoglycemic effect, Triacylglycerol (TG), hypertension, Metabolic Syndrome (MS), endothelial dysfunction, glucose homeostasis, atherosclerotic, glycolysis, Insulin Receptor (IR)

\section{INTRODUCTION}

Metabolism of dietary fructose which occurs mainly in liver, differs from that of glucose. Hepatic glucose metabolism is acutely regulated by phosphofructokinase (pfk-1), a key regulatory step of glycolysis. In contrast, fructose enters the glycolytic pathway at the triose level, by passing pfk-1. The difference in initial metabolism of fructose not only acutely affects carbohydrate metabolism by changing supply of intermediate metabolites, but also induces metabolic adaptation including changes in gene expression (Koo et al., 2008). Genes involved in carbohydrate metabolism are strongly regulated by hormones such as insulin and glucagons and are sensitive to nutritional status (Goodridge, 1987).
In animals, high fructose diets cause multiple symptoms of metabolic syndrome such as insulin resistance (Thorburn et al., 1989). Some investigators revealed a correlation between insulin resistance and defects of the NO system (Shinozaki et al., 1999; Kuboki et al., 2000) and others have shown that a defective NO system in the kidney (Cowley et al., 1995) or the whole body (Qiu et al., 1998) could be the cause of hypertension.

Nitric Oxide (NO) is produced from the conversion of L-arginine to citrulline by a family of enzymes known as NO Synthase (NOS) (Bredt and Snyder 1994). NOS exists in 3 isoforms: Neuronal NOS (nNOS), inducible NOS (iNOS) and endothelial NOS (eNOS) (Forstermann et al., 1991). Unlike constitutively expressed NOS isoforms (nNOS and 
eNOS), iNOS is regulated primarily at the transcriptional level. Induction of iNOS expression is mediated through cytokine-inducible transcription factors (Mungrue et al., 2002). Chronic inflammation has been postulated to play an important role in the pathogenesis of insulin resistance (Fujimoto et al., 2005). Inducible Nitric Oxide Synthase (iNOS) is assumed to be one of the candidates that mediate inflammation involved insulin resistance. Accumulating evidence indicates a close link between iNOS and insulin resistance.

At the molecular level, insulin resistance is correlated with impaired insulin signaling. This can involve dysfunction of cell surface components, such as Insulin Receptor (IR) as well as intracellular components like the insulin receptor substrate IRS-1 family of docking proteins and other elements of insulin signaling and glucose transport pathway Lamothe et al. (1998).

The metabolic syndrome is associated with increased morbidity and mortality of cardiovascular disease (Tjokroprawiro, 2006). It represents a clustering of metabolic disorders and cardiovascular atherogenic dyslipidemia and endothelial dysfunction (Bellomo et al., 2007).

Increasing evidence indicates that Insulin Growth Factor-1 (IGF-1) protects against endothelial dysfunction, atherosclerotic plaque development and the metabolic syndrome (Conti et al., 2004). It promotes growth and differentiation in a variety of tissue (Baker et al., 1993). It also mincs some of the metabolic actions of insulin, including stimulation of glucose and amino acids uptake and inhibition gluconeogenesis (Moses et al., 1996). These effects are largely mediated by the IGF-1 receptor, although IGF-1 can also bind to the insulin receptor with low affinity (Di Cola et al., 1997).

It is possible that low IGF-1 levels may increase cardiovascular risk by affecting insulin sensitivity and thus could be part of the polymetabolic syndrome (Spallarossa et al., 1996).

Pharmacological therapy is a critical step in the management of patients with metabolic syndrome when lifestyle modification, fail to achieve the therapeutic goals. There is no single best therapy and treatment should consist of treatment of individual components of the syndrome. It is also important to know whether drugs used in treatment, have a secondary effect, either favorable or unfavorable on insulin resistance (Deedwania and Gupta, 2006).

L-carnitine (CA, $\beta$-hydroxy- $\gamma$-trimethyl amino butyrate) is a vitamin like compound obtained from the diet that is also synthesized in the body from the essential amino acids lysine and methionine (Woodworth et al., 2004). CA has been shown to improve insulin sensitivity and could lower hepatic glucose overproduction as a consequence of its effect on fatty acids oxidation (Rajasekar et al., 2007).

The present study was designed to evaluate the amelioration of the iNOS, IGF-1 genes expression and Insulin Receptor Substrate-1 (IRS-1) in liver tissues of rats fed high fructose diet treated with L-carnitine.

\section{MATERIALS AND METHODS}

Chemicals: L-carnitine, other chemicals and solvents were of high analytical grade and were purchased from Sigma Chemical Company.

Animals and treatment: Adult male Wistar rats of body weight ranging from 120-170 g were obtained from the breeding unit of the Egyptian Organization for Biological Products and Vaccines (Helwan, Egypt). They were housed 2/cage under controlled condition 12 $\mathrm{h}$ light/12 h dark cycle. All animals received standard pellet diet for one week and water ad libitum. After acclimatization, animals were divided into the following groups consisting of 8 rats each:

Group 1: (Con)/control animals; received the control diet which contained corn starch (60 g 100 $\mathrm{g}^{-1}$ ) as a sole source of carbohydrate.

Group 2: (HFD)/ Fructose-fed rats; received a high

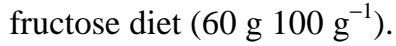

Group 3: (HFD + CA)/fructose-fed animals; received the fructose-diet and treated with L-carnitine (300 mg kg $\mathrm{mg}^{-1}$ body wt day ${ }^{-1}$, i.p.) at the beging of 3rd week of experimental period.

The animals were maintained in their respective groups for 4 weeks and body weight changes were recorded weekly. At the end of the experimental period, animals in all groups were weighed and blood samples were taken from the retro-orbital venous plexus under light ether anesthesia after a fast of $12 \mathrm{~h}$. Serum was separated by centrifuging blood samples at $3000 \mathrm{rpm}$ for $10 \mathrm{~min}$. Serum samples were aliquoted and stored at $-20^{\circ} \mathrm{C}$ until analysis, except for glucose which was determined on the same day. After blood collection, all animals were sacrificed by decapitation and for each animal liver was excised, rinsed with shield saline, weighed and rapidly frozen in liquid nitrogen then stored at $-70^{\circ} \mathrm{C}$ until assayed. 
Serum analysis: Serum was used for determination of glucose and Triacylglycerol (TG) according to the methods described by Barham and Trinder (1972) and Fossati and Prencipe (1982) respectively. The remaining part of serum was used for determination of insulin which was assayed by monoclonal immunoradiometric assay using kit supplied by Diagnostic Products Corporation (DPC) according to Marschner et al. (1974). Homeostasis Model Assessment (HOMA) correlates positively with insulin-resistance and was calculated according to Matthews et al. (1985).

Extraction of tissue lipids: Extraction was carried out according to the procedure of Refaie et al. (2005). Briefly, total lipids from tissues were extracted and homogenized in chloroform and methanol (2:1). The extraction solvent was evaporated and lipids resuspended in methanol. Cholesterol and triacylglycerol concentrations were assayed according to the method of Zlatkis et al. (1953) and Foster and Dunn (1973), respectively.

Determination of tissue MDA and NO: The concentrations of Malondialdehyde (MDA) and nitric oxide (NO as nitrite and nitrate) were estimated in the whole tissue homogenate (5\%) according to the methods of Esterbauer and Cheeseman (1990) and Moshage et al. (1995), respectively.

Gene expression of IGF-1 and iNOS by RT-PCR: Total RNA was extracted from the tissues by the acid guanidinum thiocyanate-phenol chloroform method of Shaker et al. (2009). The sequence of the primers used to amplify IGF-1 and iNOS genes was illustrated in the following Table 1.

Sequence of the primers used to amplify IGF-1, iNOS and $\boldsymbol{\beta}$-actin genes: Reverse transcription-polymerase chain reaction was done using the RT-PCR kit (Promega, Madison, WI). Briefly, 1 ug extracted RNA, 6 uL dNTP, $6 \mathrm{uL} \mathrm{5x}$ buffer and $30 \mathrm{pM}$ specific downstream primer were brought up to a total volume of $28 \mathrm{uL}$. The mixture was heated at $65^{\circ} \mathrm{C}$ for $5 \mathrm{~min}$ and chilled on ice for 5 min. Exactly, $0.5 \mathrm{uL}$ RNasin and $1 \mathrm{uL}$ AMV were added and the mixture was incubated at $42^{\circ}$ for $2 \mathrm{~h}$.

Table 1: Sequence of the primers used to amplify IGF-1, iNOS and $\beta$ actin genes

\begin{tabular}{cll}
\multicolumn{2}{c}{ actin genes } \\
\hline IGF-1: & Forward & Primer sequence \\
& Reverse & GTGTGGACCGAGGGGCTTTTACTTC \\
iNOS: & Forward & GGCTTGCCCCCTGGAAGTTTCTCTTCAAAGTC \\
& Reverse & AAGGAGCCATAATACTGGTTGATG \\
$\beta-$ actin: Forward & TGTTGTCCCTGTATGCCTCT \\
& Reverse & TAATGTCACGCACGATTTCC \\
\hline
\end{tabular}

Then, $5 \mathrm{uL}$ of cDNA was added to $200 \mathrm{uM}$ dNTP, 2.5 $\mathrm{U}$ Taq polymerase and $3.3 \mathrm{nM} \mathrm{MgCl}_{2}$ in a final volume of $30 \mathrm{uL}$. The reaction mixture was placed in a Hybaid Express thermal cycler for $3 \mathrm{~min}$ at $95^{\circ} \mathrm{C}$ and then subjected for 32 cycles of $95^{\circ} \mathrm{C}$ for $1.5 \mathrm{~min}, 55^{\circ} \mathrm{C}$ for 1 min, $72^{\circ} \mathrm{C}$ for $1.5 \mathrm{~min}$ and a final step at $72^{\circ} \mathrm{C}$ for 10 min. All the PCR products were applied to specified wells into an ethidium bromide-stained $2 \%$ agarose gel in known order, then Semi-quantitated using the gel documentation system (Bio Doc Analyzer) supplied by Biometra. The content of IGF-1 and iNOS mRNA were calculated and expressed as cDNA relative densitometric units (ratio of IGF- 1 or iNOS cDNA/ $\beta$-actin).

Liver insulin Receptor Substrate-1 (IRS-1): Western blot analysis was used to determine the liver Insulin Receptor Substrate-1(IRS-1) (ug $\mathrm{mL}^{-1}$ ) according to the method of Bezerra et al. (2000).

Statistical analysis: All results were expressed as the mean \pm SD. Statistical analysis was performed with Statistical Package for the Social Science for Windows (SPSS, version 11.0, Chicago, IL, USA). The data were analyzed by one-way Analysis Of Variance (ANOVA). To compare the difference among the groups, post hoc testing was performed by the Bonferroni test. The pvalue less than 0.05 were considered statistically significant (Dawson and Trapp, 2001).

\section{RESULTS}

The initial and final body weights of rats during the experimental periods of 4 weeks are given in Table 2. The body weights of the animals increased progressively during the experimental periods. There was trend for the fructose animals to gain more weight than other rats which was significant as compared with those of the control rats. Adminstration of Lcarnitine did not alter significantly the body weight. The relative liver weights (liver wt $(\mathrm{g})$ /body wt $(\mathrm{g})$ $\times 100)$ of the fructose groups were significantly higher than those of controls indicating hepatomegaly as response of high fructose diet.

The levels of serum glucose, insulin, HOMA index, cholesterol and TG are shown in Table 3. There were significant elevations in serum glucose, insulin levels and HOMA index as well as TG after 30 days of fructose-fed rats $(\mathrm{p}<0.0001$ for each) compared to control animals. Interperitoneal injection of $\mathrm{CA}$ to fructose-fed rats improved these parameters towards the control levels after 2 weeks of treatment. 
Am. J. Biochem. \& Biotech., 6 (3): 195-203, 2010

Table 2: Body weight changes and liver weight during the experimental period in control and experimental animals (Means \pm SD of 8 animals per group)

\begin{tabular}{|c|c|c|c|}
\hline \multirow[b]{2}{*}{ Parameters } & \multicolumn{3}{|c|}{ Experimental groups } \\
\hline & $\mathrm{CON}$ & HFD & $\mathrm{HFD}+\mathrm{CA}$ \\
\hline Initial body weight (g) & $125 \pm 8.37$ & $146.67 \pm 2.58^{\mathrm{a}}$ & $137.5 \pm 4.18^{\mathrm{a}, \mathrm{b}}$ \\
\hline Final weight (g) & $150 \pm 10.49$ & $175 \pm 8.37^{\mathrm{a}}$ & $174 \pm 6.66^{\mathrm{b}}$ \\
\hline Average weight gain $(\mathrm{g})$ & $25 \pm 4.47$ & $28.33 \pm 8.76$ & $36.5 \pm 4.23^{\mathrm{b}}$ \\
\hline Body gain (\%) & $20.0 \pm 3.47$ & $19 \pm 6.13$ & $27.0 \pm 2.92$ \\
\hline Liver weight (g) & $3.53 \pm 0.37$ & $5.53 \pm 0.41^{\mathrm{a}}$ & $5.56 \pm 0.54^{\mathrm{a}}$ \\
\hline Relative organ weight (\%) & $2.36 \pm 0.19$ & $3.16 \pm 0.15^{\mathrm{a}}$ & $3.19 \pm 0.21^{\mathrm{a}}$ \\
\hline
\end{tabular}

Relative organ wt $\%=$ liver wt $/$ body wt; ${ }^{a}: \mathrm{p}<0.001$ Vs. CON; ${ }^{b}: \mathrm{p}<0.0001$ Vs. HFD

Table 3: Metabolic serum parameters in different experimental groups (Mean $\pm \mathrm{SD}$ of 8 rats for group)

\begin{tabular}{|c|c|c|c|}
\hline \multirow[b]{2}{*}{ Parameters } & \multicolumn{3}{|c|}{ Experimental groups } \\
\hline & $\mathrm{CON}$ & HFD & $\mathrm{HFD}+\mathrm{CA}$ \\
\hline$\overline{\text { F.Glucose }\left(\mathrm{mg} \mathrm{dL}^{-1}\right)}$ & $92.2 \pm 9.8$ & $155.2 \pm 16.8^{\mathrm{a}}$ & $97.4 \pm 8.3^{\mathrm{b}}$ \\
\hline Insulin $\left(\mu \mathrm{IU} \mathrm{mL} \mathrm{mL}^{-1}\right)$ & $19.5 \pm 3.6$ & $36.3 \pm 6.7^{\mathrm{a}}$ & $28.5 \pm 6.9^{\mathrm{a}}$ \\
\hline HOMA index & $4.4 \pm 0.6$ & $13.9 \pm 2.2^{\mathrm{a}}$ & $6.9 \pm 1.6^{\mathrm{a}, \mathrm{b}}$ \\
\hline Cholesterol $\left(\mathrm{mg} \mathrm{dL}^{-1}\right)$ & $75.3 \pm 10.3$ & $84.3 \pm 12.4$ & $76.8 \pm 10.2$ \\
\hline Triacylglycerol $\left(\mathrm{mg} \mathrm{dL}^{-1}\right)$ & $78.3 \pm 12.2$ & $165.8 \pm 13.5^{\mathrm{a}}$ & $95.9 \pm 9.8^{\mathrm{a}, \mathrm{b}}$ \\
\hline
\end{tabular}

Table 4: Hepatic levels of cholesterol, triacylglycerol, MDA and NO product in experimental groups (Means \pm SD of 8 rats for each group)

\begin{tabular}{|c|c|c|c|}
\hline \multirow[b]{2}{*}{ Parameters } & \multicolumn{3}{|c|}{ Experimental groups } \\
\hline & $\mathrm{CON}$ & HFD & $\mathrm{HFD}+\mathrm{CA}$ \\
\hline Cholesterol ( $\mathrm{mg} \mathrm{g}^{-1}$ tissue homogenate) & $9.8 \pm 2.68$ & $11.25 \pm 1.37$ & $12.58 \pm 1.94$ \\
\hline Triacylglycerol ( $\mathrm{mg} \mathrm{g}^{-1}$ tissue homogenate) & $44.34 \pm 6.08$ & $83.46 \pm 4.23^{\mathrm{a}}$ & $57.31 \pm 9.2^{\mathrm{a}, \mathrm{b}}$ \\
\hline MDA (umol g ${ }^{-1}$ tissue homogenate) & $32.48 \pm 5.85$ & $50.9 \pm 0.31^{\mathrm{a}}$ & $33.59 \pm 5.5^{\mathrm{b}}$ \\
\hline NO product (um g ${ }^{-1}$ tissue homogenate) & $2.41 \pm 0.33$ & $2.56 \pm 0.124$ & $2.29 \pm 0.61$ \\
\hline
\end{tabular}

${ }^{\mathrm{a}}: \mathrm{p}<0.001$ Vs. CON; ${ }^{\mathrm{b}}$ : $\mathrm{p}<0.0001$ Vs. HFD

Concentrations of lipids, MDA and NO product in liver tissues of experimental animals were given in Table 4. Cholesterol concentration were unaltered in all the experimental animals. Triacylglycerol was significantly increased in fructose-fed rats as compared to controls $(\mathrm{p}<0.0001)$. CA administration to fructose-fed rats showed a significant decreases in both TG and MDA compared to those of HFD group. The concentrations were restored to near-normal values of control rats.

Figure 1 illustrated the levels of INOS, IGF-1 genes expression and IRS-1. The results revealed that feeding high fructose diet to rats induced significant elevation in iNOS and marked decreases in both IGF1mRNA and IRS-1 compared to those rats fed control diet studied. After treatment, L-carnitine alleviated the genes expression as well as IRS-1.

\section{DISCUSSION}

The current study provided a well defined view of fructose effects on metabolic outcome and the expression of gene involved in the metabolic pathways of fructose. The present results revealed that high fructose feeding 4 weeks caused hyperglycemia, hypertriglycerdemia and hyperinsulinemia in rats. These findings already been reported by (Nandhini et al., 2002; Thirunavukkarasu et al., 2004; Rajasekar et al., 2007; Mahfouz et al., 2009) and are consistent with those of other investigators (Thorburn et al., 1989; Dai et al., 1994). The presence of insulin resistance is indicated by higher values of HOMA. This is indicated to the presence of hyperglycemia and hyperinsulinemia which related to cardiovascular diseases Bertoluci1 et al. (2010).

Insulin resistance may occur due to a defect in insulin binding caused by decreased of insulin receptor number as recorded in this study, or affinity or defects at the level of effector molecules such as glucose transports and enzymes involved in glucose metabolism Sechi and Bartoli (1997) and Kim et al. (2000).

Suga et al. (2000) suggested that fructose feeding decreases the efficacy of insulin extraction by the liver which retards insulin clearance from the circulation. Hepatic metabolism of fructose leads to alterations in the activities of key enzymes of glucose metabolism Southgate (1995) and activation of stress sensitive pathways that may desensitize insulin signaling Kelley et al. (2003). 


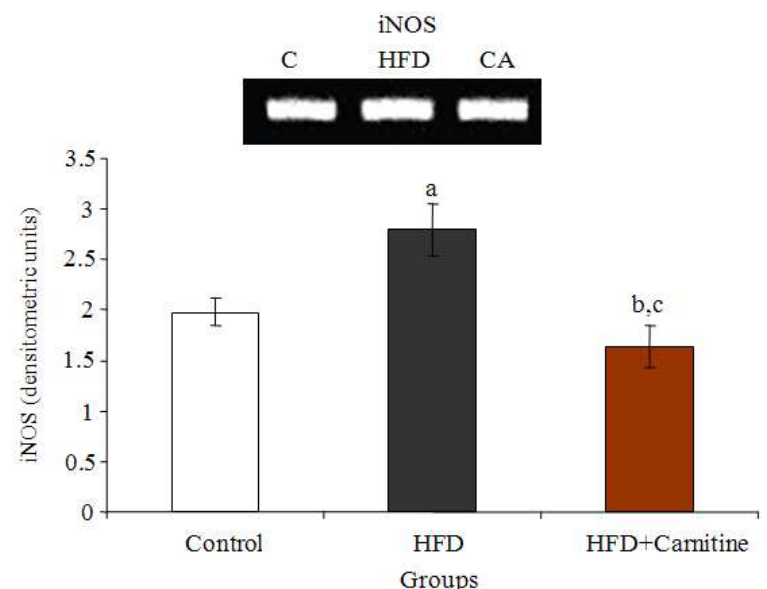

(a)

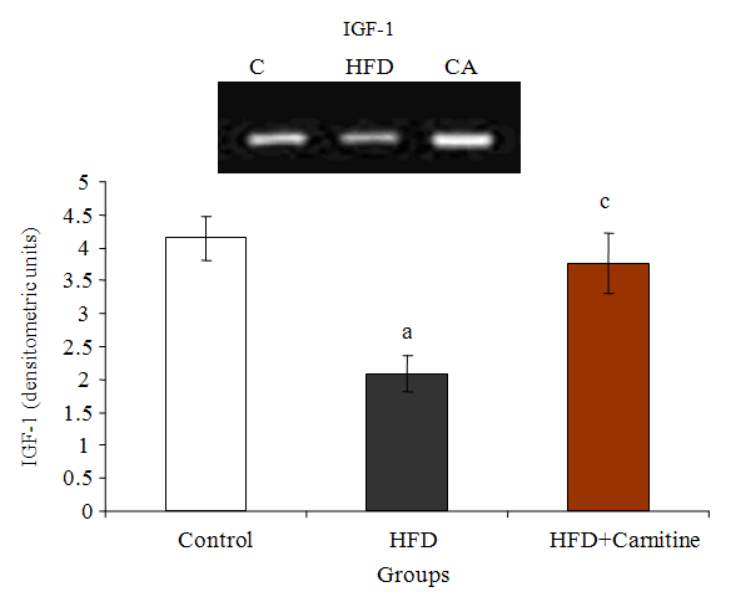

(b)

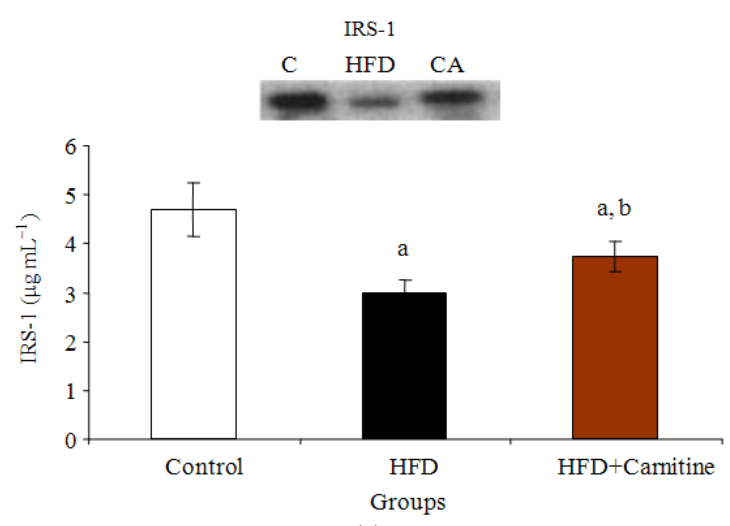

(c)

Fig. 1: Effects of high fructose diet and carnitine treatment on hepatic genes levels of iNOS, IGF$1 \mathrm{mRNA}$ and IRS-1phosphorylation levels compared with control group (values are mean \pm $\mathrm{SD}^{\mathrm{a}}$ : $\mathrm{p}<0.05$ Vs. CON; ${ }^{\mathrm{b}}: \mathrm{p}<0.05$ Vs. CON; ${ }^{\mathrm{c}}$ : $\mathrm{p}<0.005$ Vs. HFD
The present findings showed that high fructose diet induced marked elevation in hepatic levels of triacylglycerol and MDA as compared to control diet fed rats, whereas the levels of cholesterol and nitric oxide production did not show any significant alterations.Upon induction of hyperlipedemia/insulin resistance, a notable observation in the present study was the increased accumulation of TG in various insulin-sensitive tissues including liver This corresponded to an increase liver weight. Thus the significant increase in the relative liver weights of fructose group rats than those of control one indicating hepatomegaly as response to a high fructose diet Koo et al. (2008). Mechamisms or factors leading to intracellular accumulation of TG are not clear, but may be derived from increased lipogenesis and/or reduced fatty acid oxidation Kraegen et al. (2001).

With regard to the elevation of hepatic MDA in fructose fed rats Kelley et al. (2003) stated that hyperglycemia is well known to increase Reactive Oxygen Species (ROS). Hypertriglyceridemia is another factor that could enhance the formation of lipid peroxides. In addition, fructose itself enhances the reactive oxygen formation in vitro. Thus the increase in hepatic peroxides in this work could be result from a decline in cellular non enzymatic and enzymatic antioxidants potiential in fructose-fed rats.

The administration of L-carnitine to rats fed high fructose diet mitigated the adverse effects of fructose load on glucose and insulin levels. It reduces also both accumulation of TG and the peroxidation levels. This may be due to the enhancement of the fatty acid transported by carnitine into mitochondria for energy production, thereby, lowering the availability of lipid for peroxidation. These finding suggest that carnitine may improve insulin resistance Solfrizzi, et al. (2006) and Rajasekar et al. (2007)

Metabolism of dietary fructose which occurs mainly in the liver induces metabolic adaptation including changes in gene expression (Koo et al., 2008). At the molecular levels, insulin resistance is correlated with impaired insulin signaling (Lamoth et al., 1998). One of the important vascular actions of insulin in its vasodilatory effect, which is associated with $\mathrm{NO}$ production, either from endothelial cells or from perivascular neuronal cells Kuboki et al., (2000).

Nitric oxide production is controlled by Nitric Oxide Synthases (NOS), which include iNOS, eNOS and nNOS. Most importantly, iNOS is highly expressed in marcrophage. Its activation leads to organ destruction in some inflammatory and autoimmuno diseases Yoon et al. (2009).

The present results concerning the studied hepatic genes expressions and insulin receptor revealed that 
feeding high fructose diet to rats induced significant elevation in the expression of iNOS and marked decreases in both IGF-1 mRNA expression and Insulin Receptor Substrate-1 (IRS-1) compared to those rats fed control diet.

Inducible Nitric Oxide Synthase (iNOS) is assumed to be one of the candidates that mediate inflammation involved insulin resistance. Accumulating evidence indicates a close link between iNOS expression and insulin resistance Fujimoto et al., (2005). This report elucidate the elevation of the studied iNOS expression associated with insulin resistance which induced by feeding high fructose diet to rats. Inducible nitric oxide synthase has been implicated in many human diseases associated with inflammation. iNOS deficiency was shown to prevent insulin resistance. The role of iNOS in hyperglycemia and hepatic insulin resistance remains to be investigated (Fujimoto et al., 2005).

Increasing evidence suggests that Insulin like Growth Factor (IGF-1) plays a role in glucose hemeostatis, lipolysis and protein oxidation Froesch et al. (1996). The results of the present work in which rats fed $60 \%$ fructose in diet are a suitable model of rats of the metabolic syndrome (insulin resistance).

The reduced IGF-1 levels observed in the present work in accordance with the previous report of Robins (2003) who reported that reduced IGF-1 levels are independently associated with glucose intolerance and atherogenic dysilipedemia Shaker et al. (2009) reported that IGF-1 is an important metabolic regulatory hormone synthesize and released mainly by the liver and kidneys. It has hypoglycemic effects and enhances insulin sensitivity Frystyk (2004). The hypoglycemic effects of IGF-1 may be due to increasing endothelial constitutive Nitric Oxide Synthase (NOS) activity. IGF1 by interacting with a tyrosine kinase membrane receptor linked to insulin receptor substrate 1 and 2 , causes phosphorylation of phosphatidyl inositol 3kinase which activates the serine/threonine kinase Conti et al. (2004). This pathway phosphorylates constitutive NOS leading to nitric oxide production with multiple metabolic and vascular protective effects including glucose transport in muscle and fat and inhibition of hepatic gluconeogenesis Frystyk (2004).

As mention before, there was a significant reduction in the levels of hepatic IRS-1 tyrosine phosphorylation in rats fed high fructose diet compared to controls. This is in agreement with report of Bezerra et al. (2000) who stated that there was a significant reduction in the levels of hepatic and muscle IRS-1 tyrosine phosphorylation. The decrease observed in this study may be of biological importance because a reduction of receptor phosphorylation has been correlated with insulin resistance in different animal models Saad et al. (1997). Also Catena et al. (2003) concluded that the decreased number of insulin receptors occurring at the level of gene expression is present in skeletal muscles and liver of fructose fed rats and might contribute to insulin resistance in his model.

In the present work, fructose-fed rats treated with L-carnitine (i.p) showed significant decrease in iNOS expression and pronounced increases in both IGF-1 mRNA expression and IRS-1 receptors compared with values obtained from untreated fructose fed rats. These findings suggest that carnitine may mitigated insulin resistance through the regulation of studied genes expression.

Many investigators reported that inhibition of iNOS expression has been proposed to be a new mechanism of actions of insulin sensitizers Da Ros et al. (2004) and Pilon et al. (2004). It has been shown that iNOS plays an important role in the pathogenesis of insulin resistance in vivo (Fujimoto et al., 2005). They demonstrated that iNOS inhibitor prevented fasting hyperglycemia and mitigated insulin resistance. In the last few years, increasing evidence has suggested that IGF-1 may have a role in both glucose homeostasis and cardiac diseases Sesti et al. (2005).

\section{CONCLUSION}

The most important finding of the present analysis is the close association between hepatic genes expression (iNOS and IGF-1) and IRS-1 receptor and insulin resistance. The therapeutic effects of L-carnitine in hyperinsulinemic rats may be due to the improvement of inflammation resulting from insulin resistance through amelioration of the studied genes expression. These data indicate that IGF-1 and iNOS have the characteristics to be markers for the metabolic syndrome. This suggest that low IGF-1 levels may be a useful marker for identifying subjects at risk for cardiovascular disease.

\section{REFERENCES}

Baker, J., J.P. Liu, E.J. Robertson and A. Efstratiadis, 1993. Role of insulin-like growth factors in embryonic and postnatal growth. Cell, 75: 73-82. PMID: 8402902

Barham, D. and P. Trinder, 1972. An improved color reagent for the determination of blood glucose by the oxidase system. Analyst, 97: 142-145. PMID: 5037807 
Bellomo, A., M. Mancinella, G. Troisi, E. Ettorre and V. Marigliano, 2007. Diabetes and Metabolic Syndrome (MS). Arch. Gerontol. Geriatr., 1: 61-67. PMID: 17317435

Bertoluci1, M.C., A.S. Quadros, R. Sarmento-Leite and B.D. Schaan, 2010. Insulin resistance and triglyceride/HDLc index are associated with coronary artery disease. Diabetol. Metab. Syndr., 2: 11. PMCID: PMC2830967

Bezerra, R.M., M. Ueno, M.S. Silva, D.Q. Tavares and C.R. Carvalho et al., 2000. A high fructose diet affects the early steps of insulin action in muscle and liver of rats. J. Nutr., 130: 1531-1535. PMID: 10827205

Bredt, D.S. and S.H. Snyder, 1994. Nitric oxide: A physiologic messenger molecule. Annu. Rev. Biochem., 63: 175-195. PMID: 7526779

Catena, C., G. Giacchetti, M. Novello, G. Colussi and A. Cavarape et al., 2003. Cellular mechanisms of insulin resistance in rats with fructose induced hypertension. Am. J. Hypertens., 16: 973-978. PMID: 14573337

Conti, E., C. Carrozza, E. Capoluongo, M. Volpe and F. Crea et al., 2004. Insulin-like growth factor1 as a vascular protective factor. Circulation, 110: 2260-2265. PMID: 15477425

Cowley, A.W. Jr, D.L. Mattson, S. Lu and R.J. Roman, 1995. The renal medulla and hypertension. Hypertension, 25: 663-673. PMID: 7721413

Da Ros, R., R. Assaloni and A. Ceriello, 2004. The preventive anti-oxidant action of thiazolidinediones: A new therapeutic prospect in diabetes and insulin resistance. Diabet. Med., 21: 1249-1252. PMID: 15498094

Dai, S., M.E. Todd, S. Lee and J.H. McNeill, 1994. Fructose loading induces cardiovascular and metabolic changes in nondiabetic and diabetic rats. Can. J. Physiol. Pharmacol., 72: 771-781. PMID: 7828085

Dawson, B. and R.G. Trapp, 2001. Basic and Clinical Biostatistics. 3rd Edn., PBL, Lange Medical Books/McGraw-Hill, USA. ISBN: 0-8385-0510-4.

Deedwania, P.C. and R. Gupta, 2006. Management issues in the metabolic syndrome. J. Assoc. Phys. Ind., 54: 797-810. PMID: 17214277

Di Cola, G., M.H. Cool and D. Accili, 1997. Hypoglycemic effect of insulin-like growth factor1 in mice lacking insulin receptors. J. Clin. Invest., 99: 2538-2544. PMID: 9153298

Esterbauer, H. and K.H. Cheesman, 1990. Determination of aldehyde lipid peroxidation products: Malonaldehyde and 4-hydroxynonenal. Methods Enzymol., 186: 407-410. PMID: 2233308
Forstermann, U., H.H. Schmidt, J.S. Pollock, H. Sheng and J.A. Mitchell et al., 1991. Isoforms of nitric oxide synthase. Characterization and purification from different cell types. Biochem. Pharmacol., 42: 1849-1857. PMID: 1720618

Fossati, P. and L. Prencipe, 1982. Serum triglycerides determined colorimetrically with an enzyme that produces hydrogen peroxide. Clin. Chem., 28: 2077-2080. PMID: 6812986

Foster, C.S. and O. Dunn, 1973. Stable reagents for determination of serum triglycerides by a colorimetric Hantzich condensation method. Clin. Chem., 19: 338-340. ISSN: 0009-9147

Froesch, E.R., M.A. Hussain, C. Schmid and J. Zapf, 1996. Insulin-like growth factor I: Physiology, metabolic effects and clinical uses. Diabetes Metab Rev., 12: 195-215. PMID: 8959385

Frystyk, J., 2004. Free insulin-like growth factorsmeasurements and relationships to growth hormone secretion and glucose homeostasis. Growth Horm IGF Res., 14:337-375. PMID: 15336229

Fujimoto, M., N. Shimizu, K. Kunii, J.A. Martyn and K. Ueki et al., 2005. A role for iNOS in fasting hyperglycemia and impaired insulin signaling in the liver of obese diabetic mice. Diabetes, 54: 1340-1348. DOI: 10.2337/diabetes.54.5.1340

Goodridge, A.G., 1987. Dietary regulation of gene expression: Enzymes involved in carbohydrate and lipid metabolism. Annu. Rev. Nutr., 7: 157-185. PMID: 3300731

Kelley, G.L., G. Allan and S. Azhar, 2003. High dietary fructose induces a hepatic stress response resulting in cholesterol and lipid dysregulation. Endocrinology, 145: 548-555. PMID: 14576175

Kim, J.K., O. Gavrilova, Y. Chen, M.L. Reitman and G.I. Shulman, 2000. Mechanism of insulin resistance in A-ZIP/F-1 fatless mice. J. Biol. Chem., 275: 8456-8460. PMID: 10722680

Koo, H.Y., M.A. Wallig, B.H. Chung, T.Y. Nara and B.H. Cho et al., 2008. Dietary fructose induces a wide range of genes with distinct shift in carbohydrate and lipid metabolism in fed and fasted rat liver. Biochim. Biophys. Acta., 1782: 341-348. PMID: 18346472

Kraegen, E.W., G.J. Cooney, J. Ye and A.L. Thompson, 2001. Triglycerides, fatty acids and insulin resistance-hyperinsulinemia. Exp. Clin. Endocrinol. Diabetes, 109: 516-526. PMID: 11453039

Kuboki, K., Z.Y. Jiang, N. Takahara, S.W. Ha and M. Igarashi et al., 2000. Regulation of endothelial constitutive nitric oxide synthase gene expression in endothelial cells and in vivo: A specific vascular action of insulin. Circulation, 101: 676-681. PMID: 10673261 
Lamothe, B., A. Baudry, P. Desbois, L. Lamotte and D. Bucchini et al., 1998. Genetic engineering in mice: Impact on insulin signaling and action. Biochem. J., 335: 193-204. PMID: 9761714

Mahfouz, M.H., H.M. Ghanem and M.A. Mohamed, 2009. Therapeutic effect of L-carnitine on sialic acid, soluble Fas (sFas) and other biochemical variables in hyperinsulinemic rats. Life Sci. J., 6: 76-82. ISSN: 1097-8135

Marschner, I.P., F. Bottermann, R. Erhardt, Linke and G. Loffler et al., 1974. Group experiments on the radioimmunological insulin determination. Horm. Metab. Res., 6: 293-296. PMID: 4413601

Matthews, D.R., J.P. Hosker, A.S. Rudenski, B.A. Naylor and D.F. Treacher et al., 1985. Homeostasis model assessment: Insulin resistance and beta-cell function from fasting plasma glucose and insulin concentrations in man. Diabetologia, 28: 412-419. DOI: $10.1007 / \mathrm{BF} 00280883$

Moses, A.C., S.C. Young, L.A. Morrow, M. O'Brien and D.R. Clemmons, 1996. Recombinant human insulin-like growth factor I increases insulin sensitivity and improves glycemic control in type II diabetes. Diabetes, 45: 91-100. PMID: 8522066

Moshage, H., B. Kok, J. Huizenga and P. Junsen, 1995. Nitrite and nitrate determinations in plasma: A critical evaluation. Clin. Chem., 41: 892-896. PMID: 7768008

Mungrue, I.N., R. Gros, X. You, A. Pirani and A. Azad et al., 2002. Cardiomyocyte overexpression of iNOS in mice results in peroxynitrite generation, heart block and sudden death. J. Clin. Invest., 109: 735-743. DOI: $10.1172 / \mathrm{JC} 10213265$

Nandhini, A.T., S.D. Balakrishnan and C.V. Anuradha, 2002. Response of liver antioxidant system to taurine in rats fed high fructose diet. Ind. J. Exp. Biol., 40: 1016-1019. PMID: 12587730

Pilon, G., P. Dallaire and A. Marette, 2004. Inhibition of inducible nitric-oxide synthase by activators of AMP-activated protein kinase: A new mechanism of action of insulin-sensitizing drugs. J. Biol. Chem., 279: 20767-20774. DOI: 10.1074/jbc.M401390200

Qiu, C., D. Muchant, W.H. Beierwaltes, L. Racusen and C. Baylis, 1998. Evolution of chronic nitric oxide inhibition hypertension: Relationship to renal function. Hypertension., 31: 21-26. PMID: 9449385

Rajasekar, P. and C.V. Anuradha, 2007. Effect of Lcarnitine on skeletal muscle lipids and oxidative stress in rats fed high-fructose diet. Exp. Diabetes. Res., 2007: 72741. PMID: 17641743
Refaie, F.M., A.Y. Esmat, S.M. Abdel Gawad, A.M. Ibrahim and M.A. Mohamed, 2005. The antihyperlipidemic activities of $4(3 \mathrm{H})$ quinazolinone and two halogenated derivatives in rats. Lipids in Health and Disease, 4:22-32. DOI: 10.1186/1476-511X-4-22

Robins, S.J., 2003. Cardiovascular disease with diabetes or the metabolic syndrome: Should stations or fibrates be first line lipid therapy? Curr. Opin. Lipidol., 14: 575-583. PMID: 14624134

Saad, M.J., L. Maeda, S.L. Brenelli, C.R. Carvalho and R.S. Paiva et al., 1997. Defects in insulin signal transduction in liver and muscle of pregnant rats. Diabetologia, 40: 179-186. PMID: 9049478

Sechi, L.A. and E. Bartoli, 1997. Mechanisms of insulin resistance leading to hypertension: What we can learn from experimental models. J. Invest. Med., 45: 238-351. PMID: 9249996

Sesti, G., A. Sciacqua, M. Cardellini, M.A. Marini and R. Maio et al., 2005. Plasma concentration of IGFI is independently associated with insulin sensitivity in subjects with different degrees of glucose tolerance. Diabetes Care, 28: 120-125. doi: 10.2337/diacare.28.1.120

Shaker, O.G., D.A. Sourour and M. Taha, 2009. Effects of statins on insulin-like growth factor-1 gene expression in fructose induced metabolic syndrome in rats. Open Endocrinol. J., 3: 28-33. ISSN: 1874-2165

Shinozaki, K., A. Kashiwagi, Y. Nishio, T. Okamura and Y. Yoshida et al., 1999. Abnormal biopterin metabolism is a major cause of impaired endothelium-dependent relaxation through nitric oxide/O2- imbalance in insulin-resistant rat aorta. Diabetes, 48: 2437-2445. DOI: 10.2337/diabetes. 48.12.2437

Solfrizzi, V., C. Capurso, A.M. Colacicco, A.D. Introno and C. Fontana et al., 2006. Efficacy and tolerability of combined treatment with L-carnitine and simvastatin in lowering lipoprotein (a) serum levels in patients with type 2 diabetes mellitus. Atherosclerosis, 188: 455-461. DOI: 10.1016/j.atherosclerosis.2005.11.024.

Southgate, D.A.T., 1995. Digestion and metabolism of sugars. Am. J. Clin. Nutr., 62: 203S-211S.

Spallarossa, P., C. Brunelli, F. Minuto, D. Caruso and M. Battistini et al., 1996. Insulin-like growth factor-I and angiographically documented coronary artery disease. Am. J. Cardiol., 77: 200-202. PMID: 8546095 
Suga, A., T. Hirano, H. Kageyama, T. Osaka and Y. Namba et al., 2000. Effects of fructose and glucose on plasma leptin, insulin and insulin resistance in lean and VMH-lesioned obese rats. Am. J. Physiol. Endocrinol. Metab., 278: 677-683. PMID: 10751202

Thirunavukkarasu, V., A.T.A. Nandhini and C.V. Anuradha, 2004. Cardiac lipids and antioxidant status in high fructose rats and the effect of alphalipoic acid. Nutr. Metab Cardiovasc Dis., 14: 351357. PMID: 15853119

Thorburn, A.W., L.H. Storlien, A.B. Jenkins, S. Khouri and E.W. Kraegen, 1989. Fructose-induced in vivo insulin resistance and elevated plasma triglyceride levels in rats. Am. J. Clin. Nutr., 49: 1155-1163. PMID: 2658534

Tjokroprawiro, A., 2006. New approach in the treatment of T2DM and metabolic syndrome (focus on a novel insulin sensitizer). Acta Med. Indones., 38: 160-166. PMID: 17119268
Woodworth, J.C., J.E. Minton, M.D. Tokach, J.L. Nelssen and R.D. Goodband et al., 2004. Dietary L-carnitine increases plasma leptin concentrations of gestating sows fed one meal per day. Domest Anim. Endocrinol., 26: 1-9. PMID: 14732448

Yoon, W.-J., Y.M. Ham, S.-S. Kim, B.-S. Yoo and J.Y. Moon et al., 2009. Suppression of proinflammatory cytokines, iNOS and COX-2 expression by brown algae Sargassum micracanthum in RAW 264.7 macrophages. Eur. Asia J. Biol. Sci., 3: 130-143. DOI:10.5053/ejobios.2009.3.0.17

Zlatkis, A., B. Zak and A.J. Boyle, 1953. A new method for the direct determination of serum cholesterol. J. Lab. Clin. Med., 41: 486-492. PMID: 13035283 